\title{
Induction Motor with Spiral Sheet Rotor
}

\author{
${ }^{(1)}$ Mujal Rosas, Ramon; ${ }^{(2)}$ Boix Aragonès, Oriol, Senior Member, IEEE; ${ }^{(3)}$ Colom Fajula, Xavier; \\ ${ }^{(1),(2)}$ Electrical Engineering Department. ${ }^{(3)}$ Chemical Engineering Department \\ mujal@ee.upc.edu; boix@ee.upc.edu; Xavier.colom@upc.edu
}

\begin{abstract}
Improvements in torque at low currents using a rotor with spiral sheets are analyzed. Several rotors and stators have been built combining different constructive and mechanical characteristics of the related elements: inertias, constructive materials, geometrical shapes of the sheets and geometrical disposition of the sheets. These different types of motors have been simulated using computer aided tools and then tested in the laboratory. Finally, four stators $(1000,1500,1500$-type $A$, and $3000 \mathrm{rpm}$ ) with the same constructive parameters, have been simulated and tested with the following rotors types: solid rotor, solid rotor with diamagnetic rings, drag cup, and simple and double squirrel cage rotor; the results have been compared to those obtained with the seven variants of spiral sheet rotor presented in this paper.
\end{abstract}

Index Terms-Electric machines, Special machine, Spiral sheet rotor, Three-Phase asynchronous motor.

\section{INTRODUCTION}

$\mathrm{T}$ he rotors of conventional asynchronous motors are formed by magnetic sheets packed above the shaft of the machine. The rotating magnetic field created by the stator, induces currents parallel to the shaft and so upright to the rotor sheets [1]. Those currents cannot flow between the sheets if they are electrically isolated, requiring the intervention of conventional squirrel cage rings to close the electric circuit so the rotor currents can circulate.

This work was supported by "Ministerio de Ciencia y Tecnología de España" under the DPI 2004-03180 Research Project.

Ramon Mujal Rosas is professor in the Electrical Engineering Department of the Technical University of Catalonia. Colom St. 1, 08222 Terrassa (Spain). Phone: 0034-93-739-8035; Fax: 0034-93-739-8236; e-mail: mujal@ee.upc.edu.

Oriol Boix Aragonès is professor in the Electrical Engineering Department of the Technical University of Catalonia. Diagonal Av. 647, 08028 Barcelona Phone: 0034-93-401-5889; fax: 0034-93-401-7433; e-mail: boix@ee.upc.edu.

Xavier Colom Fajula is professor in the Chemical Engineering Department of the Technical University of Catalonia. Colom St. 1, 08222 Terrassa (Spain) Phone: 0034-93-739-8044; Fax: 0034-93-739-82-25; e-mail: xavier.colom@upc.edu.
Typical configurations of three-phase asynchronous motors [2] are shown in figure 1 and described in the following points:

1) Single cage winding with high resistance and minimal inductance.

2) Deep slot cage, with low resistance and progressive reactance with the slip.

3) Low resistance and low reactance slot.

4) Finally, there are additional configurations of double and triple cage combining characteristics of the previous dispositions, with different resistance and reactance values for each cage.

In all of these dispositions, currents go through the cage conductors [3], while magnetic field is through the sheets. The performance of these motors depends on the magnetic field, the current and the distance from the conductor to the shaft.

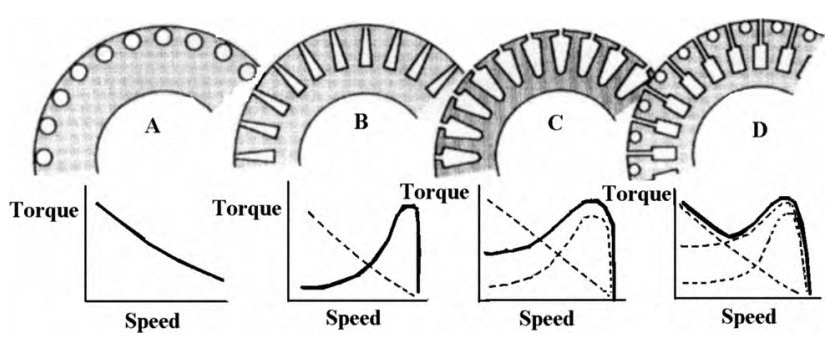

Fig. 1. Typical configurations of three-phase asynchronous motors.

\section{PROTOTYPES DESCRIPTION}

As an example, the basic mechanical characteristics of some tested rotors are presented in table I [3]. These rotors used have the same dimensions and they are assembled to stators of $1000 \mathrm{rpm}, 1500 \mathrm{rpm}$ and $3000 \mathrm{rpm}$, the latter having the same constructive parameters. 
TABLE I

MAIN MECHANICAL CHARACTERISTICS OF ROTORS

\begin{tabular}{lcccc}
\hline \hline \multicolumn{1}{c}{ Rotor types } & $\begin{array}{c}\text { Mass } \\
(\mathrm{kg})\end{array}$ & $\begin{array}{c}\text { Inertia } \\
\left(\mathrm{kg} \cdot \mathrm{m}^{2}\right)\end{array}$ & $\begin{array}{c}\text { Kinetic energy } \\
\text { at } 1500 \mathrm{rpm}(\mathrm{J})\end{array}$ & $\begin{array}{c}\text { Rotor } \\
\text { dimensions } \\
(\mathrm{mm})\end{array}$ \\
\hline Squirrel cage & 3.440 & $2.717 \cdot 10^{-3}$ & 33.519 & $79.5 \times 71$ \\
Solid rotor & 3.620 & $2.860 \cdot 10^{-3}$ & 35.283 & $79.5 \times 71$ \\
Solid with ring & 3.580 & $2.828 \cdot 10^{-3}$ & 34.889 & $79.5 \times 71$ \\
Diamagnetic & 0.620 & $4.898 \cdot 10^{-4}$ & 6.0426 & $79.5 \times 71$ \\
hollow rotor & & $3.465 \cdot 10^{-3}$ & 30.411 & $79.5 \times 71$ \\
Winding rotor & 3.120 & $2.4656 .19 \times 71$ \\
Spiral sheet, A & 3.160 & $2.496 \cdot 10^{-3}$ & 30.793 & $79.5 \times 71$ \\
Spiral sheet, B & 3.236 & $2.556 \cdot 10^{-3}$ & 31.533 & $79.5 \times 71$ \\
Spiral sheet, D & 3.040 & $2.401 \cdot 10^{-3}$ & 29.621 & $79.5 \times 71$ \\
Spiral sheet, Z & 3.230 & $2.625 \cdot 10^{-3}$ & 32.384 & $79.5 \times 71$ \\
\hline \hline
\end{tabular}

\section{THREE PHASE ASYNCHRONOUS TORQUE MOTOR}

The so called "torque-motor" [5] is a three - phase asynchronous motor with the stator built in a classical way, but its rotor is constructed by a hard sheet iron cylinder (with small hysteresis cycle). With this kind of rotor a higher useful section for flux circulation is obtained, but one of the drawbacks of this motor is the fact that the lines of magnetic fields go through its core reaching considerable depths, inducing an EMF that makes it weaker.

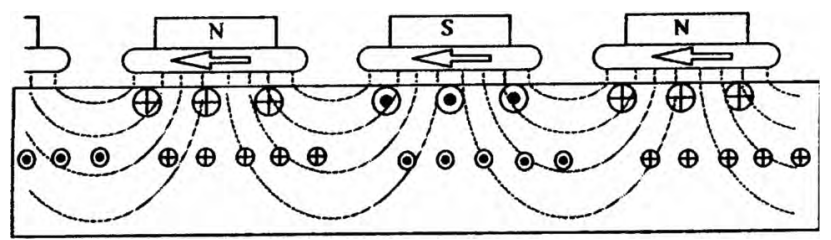

Fig. 2. Section of a "three-phase asynchronous torque-motor".

A current circulating at greater depth has lower participation in the generation of torque, owing to the following causes:

1) Lower distance between the currents and the shaft of the motor.

2) The higher reactance results in lower power factor although the losses in the copper are the same as if they circulate on the periphery.

In figure 2, this phenomenon is illustrated, showing that the deeper currents are weaker, and have also some delay in the direction of the displacement.

\section{MOTOR WITH SPIRAL SHEET ROTOR}

Forming a rotor with spiral shape sheets [8], distributed in a radial disposition around the shaft, it is possible to generate a magnetic field in the rotor periphery, inducing peripheral emf, and currents along the same sheets, that are only active in their periphery.

The peripheral currents of this rotor have more section to circulate, compared to a normal cage rotor current, as can be seen in figure 3.
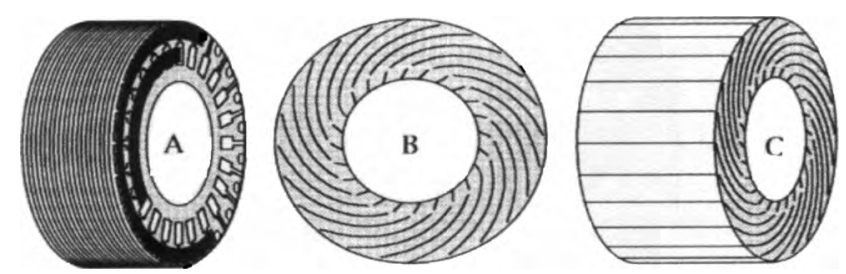

Fig. 3. Rotors: with double cage A. Spiral sheet rotors B and C types

Figure 4 shows a plain representation of the disposition of the sheets [9]. There are two zones: one with active currents going through and the other is used to receive the possible returning currents (A returning currents proposal).

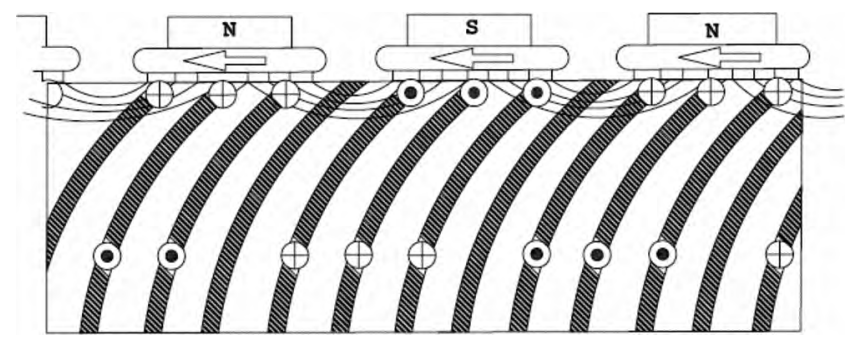

Fig. 4. Section of a "three-phase asynchronous torque-motor".

The returning currents can be established in two ways, as shown in figure 5:

A) Through short-circuit rings. In this type of construction the resistance corresponds to that of the outside of the iron sheets that form the rotor. This is because the short-circuit ring can be built in a big section, and its resistance can be despised compared to the resistance offered by the superficial sheets layers. This solution is not suitable for manufacturing; however it gives the best results.

B) Part of the same sheet is a pathway for back currents that do not generate torque. In this case, the zones of active currents that generate torque are placed in the sheet periphery, and are affected by the magnetic field, leaving high sheet section as a return way.

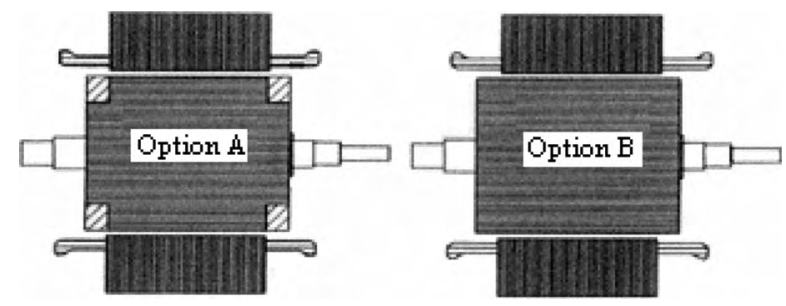

Fig. 5. A: with short-circuit rings. B: without short-circuit rings.

\section{PROTOTYPE DESCRIPTION}

Several types of rotor have been constructed; each one is formed by a group of magnetic sheets radially disposed with the head directly above the shaft. Those sheets completely cover the outside cylindrical surface of the shaft [8]. 
When sheet density is constant, in order to eliminate free space that would result in increasing the radial distance, the sheets have been rolled above the others, as if the rotor were formed by a group of spinning sheets; as can be seen in figure 6 .

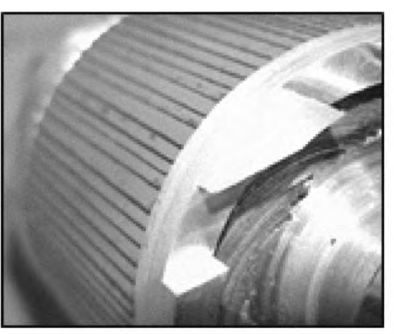

a)

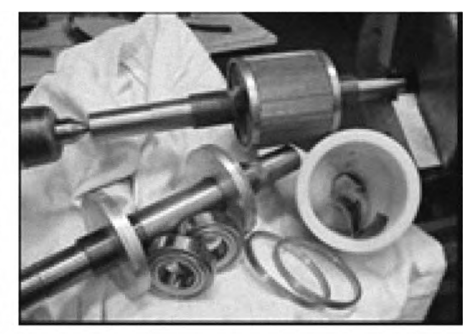

b)
Fig. 6. Rotor with spiral sheet in manufacturing phase. a) Type A, b) Type Z

In this way the generated flux in the stator windings, that is the rotating magnetic field falls in an inclined way into the sheets, producing some eddy currents which circulate in presence of the mentioned flux, generating some antagonistic torques. The outside torque is bigger than the inside one, because the radial distance is much higher, which results in a net rotation corresponding to the difference between the mentioned torques (figure 7).

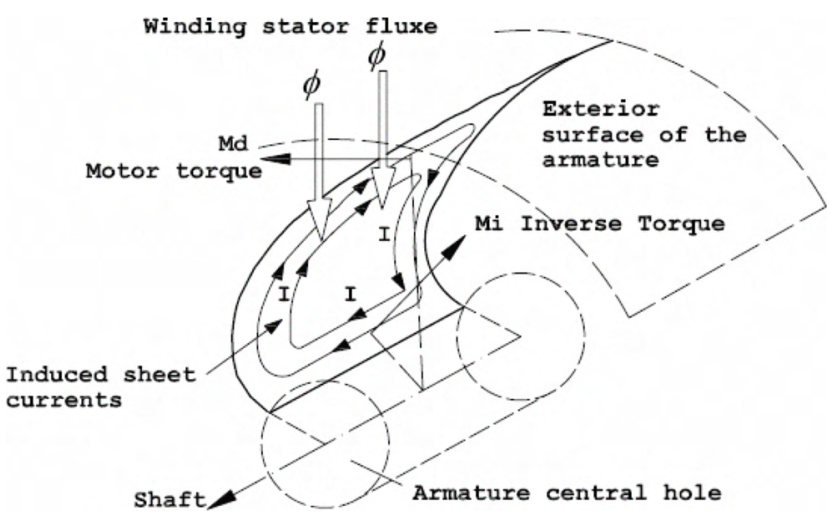

Fig. 7. Rotating magnetic field, eddy currents and antagonistic torques.

\section{CONSTRUCTION}

To construct the proposed prototype rotor a radically different process from the construction of a conventional squirrel cage rotor is followed.

It has been indicated that in this new rotor, the sheets do not have any slots. So, to have them perfectly joined without air spaces between them, its shape must have a perfect definite profile. This profile is reached by the shaping with a tool or matrix to deform every piece or sheet, giving the precise shape that is described as follows.

If a rotor of interior radius $R$ is considered, formed by $n$ sheets of a thickness $e$, where this thickness is very small compared to $R$, and with an outside radius $R_{E}$, then the trigonometric ratios shown in figure 8 are obtained.

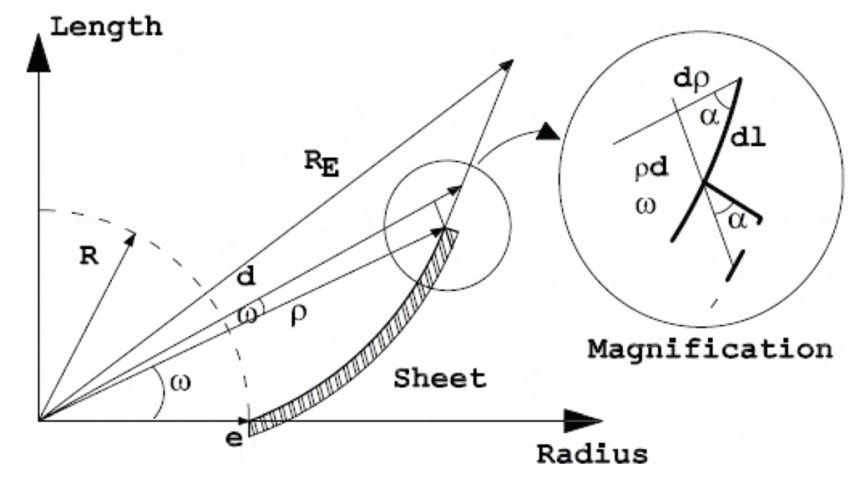

Fig. 8. Trigonometric relations of the sheet rotor.

\section{$A$. Calculus of length of the sheet as a function of the interior radius $R$, and the exterior radius $R_{E}$}

If the perimeter of the sheets is equal and growth with inside radius $\mathrm{R}$, and outside radius $\mathrm{RE}$, then:

$$
2 \cdot \pi \cdot R=e \cdot n \quad 2 \cdot \pi \cdot \rho=\frac{e \cdot n}{\cos \alpha} \quad \frac{R}{\rho}=\cos \alpha
$$

Also, from the differential triangle, knowing that both angles $\alpha$ are the same because of the perpendicular sides, then:

$$
d l=\frac{d \rho}{\cos \alpha} \quad \text { or } \quad d l=\frac{\rho \cdot d \rho}{R}
$$

And by integrating:

$$
[L]=\left[\frac{\rho^{2}}{2 \cdot R}\right]_{R}^{R_{E}} \quad \text { and } \quad L=\frac{\left(R_{E}^{2}-R^{2}\right)}{2 \cdot R}
$$

This is an expression that relates the length of every sheet with the interior radius $R$ and the exterior one $R_{E}$, like the sheet illustrated in figure 9.

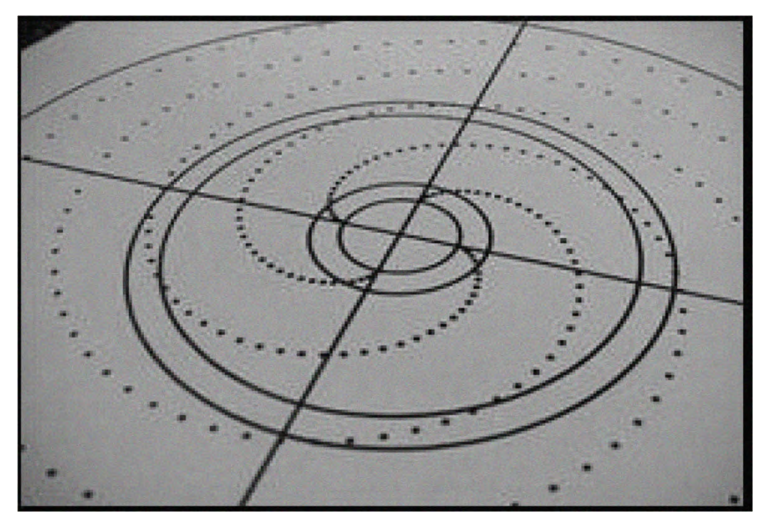

Fig. 9. Exact shape of the spiral sheets rotor.

\section{B. Calculus of the sheets curvature radius}

Despite the knowledge of the relationship between length and inside and outside radius, is not enough to determine the exact shape that the sheets acquire. Another parameter is 
necessary; the sheet curvature radius (sheets curve in every differential length). Starting from the known identities, the following equations hold:

$$
\begin{gathered}
\cos \alpha=\frac{R}{\rho} \text { and } \operatorname{tg} \alpha=\frac{(\rho \cdot d w)}{d \rho} \\
\frac{d \rho}{d w}=\frac{\rho}{\operatorname{tg} \alpha}=\frac{\rho \cdot\left(\frac{R}{\rho}\right)}{\sqrt{\left(1-\cos ^{2} \alpha\right)}}=\frac{\rho \cdot R}{\sqrt{(R-\rho)}}=\rho^{\prime}
\end{gathered}
$$

This is the differential polar equation that must be integrated between $R_{E}$ and $R$ limits to obtain, in every sheet's point, the required curve that accomplishes the objectives desired: perfect sheet junction without changing curve radius.

\section{ANALYSIS OF CONDUCTIVITY}

This section analyzes the distribution of currents vs. the flux density of foil motors with different electric conductivity (3, 12 and $60 \mathrm{MS} / \mathrm{m}$ each one). The induction distribution and also the current density in the foils for $5 \mathrm{~Hz}$ rotor frequency are analyzed [7].
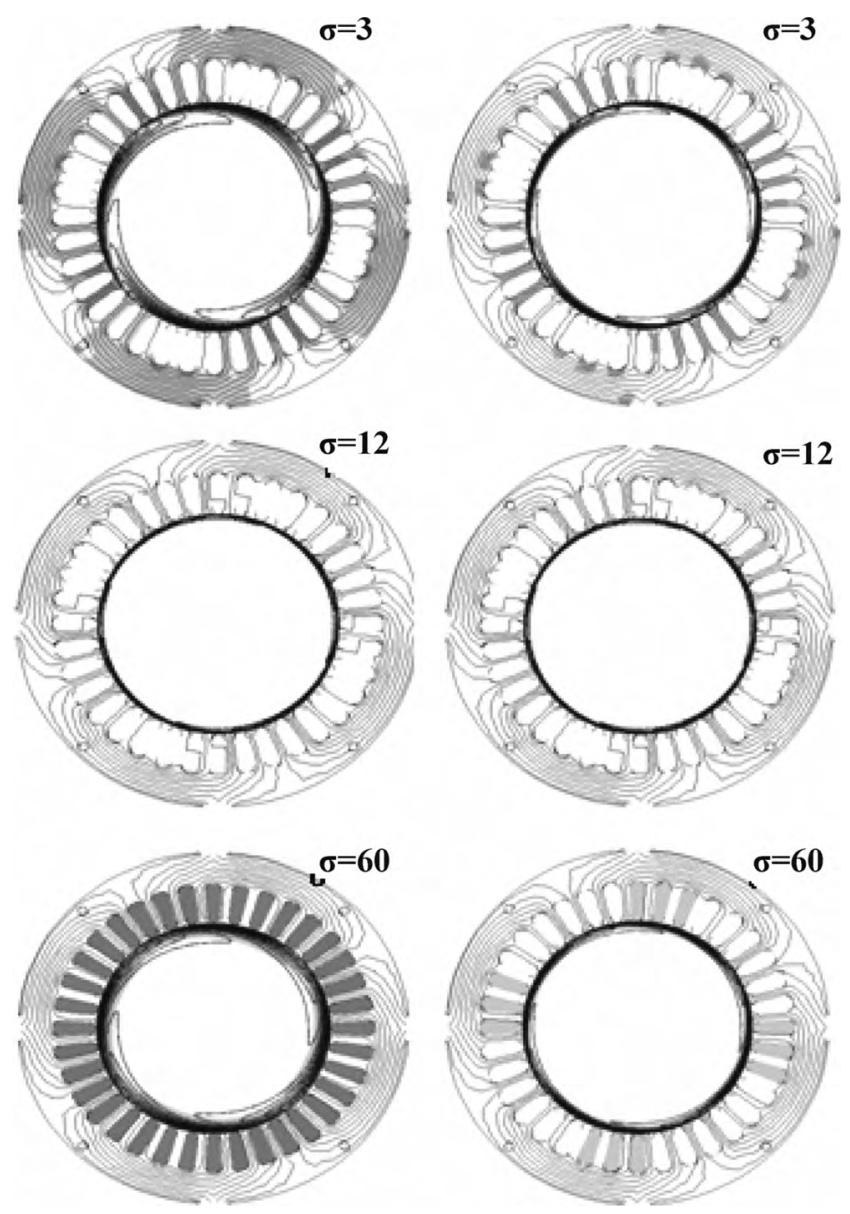

Fig. 10. Flux and current densities simulations for different conductivity values. Motor with spiral sheet rotor type A.
Figure 10 shows that by increasing conductivity of the material, the current distribution becomes more superficial. From the analysis we can appreciate the existence of a field created by the rotor as the conductivity of the material increases. According to the simulations, the net field in the motor is weaker as the rotor produces a bigger field. This phenomenon is only possible if there is a bigger phase between the two fields (stator and rotor). This space phase means a predictable change in the resistance and reactance properties in the rotor.

A bigger conductivity obviously implies a more inductive loading that generates a reactive power. The optimization in the selection of materials relapses in the evaluation of the product of the primary current by the factor of motor power with the useful torque that it can develop. This conclusion is very important because it is applicable to any part of the motor when deciding the application of the best materials.

Supposing the reactance variation in the rotor is very small, since its frequency is weak, it is possible to approach the variation of the angle of temporary phase out between the rotor current and the electromotive force as:

$$
\theta=\operatorname{arctg}(K \cdot \sigma)
$$

Where $\sigma$ is the conductivity. Then, the width variation of $B_{\text {rotor }}$ in relation to the $I_{\text {rotor }}$ variation gives:

$$
\partial B \propto \partial I \quad \text { and } \quad I=\frac{\vec{E}}{R_{\text {rotor }}+j \cdot X_{\text {rotor }}}
$$

With their corresponding module :

$$
|\vec{I}|=\frac{1}{R_{\text {rotor }}^{2}+X_{\text {rotor }}^{2}} \cdot\left|\vec{E} \cdot\left(R_{\text {rotor }}-j \cdot X_{\text {rotor }}\right)\right|=\frac{E}{\sqrt{R_{\text {rotor }}^{2}+X_{\text {rotor }}^{2}}}
$$

Finally, making a series development:

$$
|I| \propto \frac{1}{X_{\text {rotor }}}-\frac{1}{2 \cdot X_{\text {rotor }}^{3}} \cdot R_{\text {rotor }}^{2}
$$

Graphically the dependence of the current module with the conductivity, for very small $R_{\text {rotor }}$ gives:

$$
|I|=K_{1}-\frac{K_{2}}{\sigma^{2}}
$$

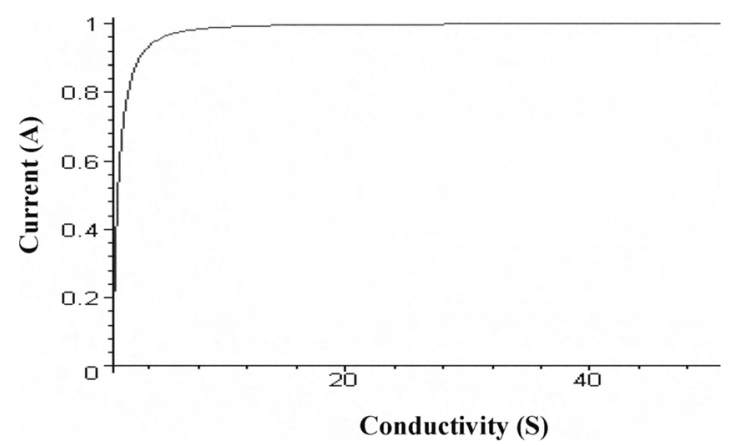

Fig. 11. Current-conductivity in a motor with spiral sheet rotor 
The obstacles of air found in the rotor flow facilitate the creation of a characteristic reluctance of the motor. This phenomenon facilitates, in transitory, a very quick response. The high reluctance also comes accompanied by a low inertia that also supposes a low mechanical and electric time constant.

\section{CURRENT DENSITY DISTRIBUTION}

Through FEMM simulations (figure 12) the distribution of current density in the rotor [6] can be determined. The real component of this current density is represented in figure 13.

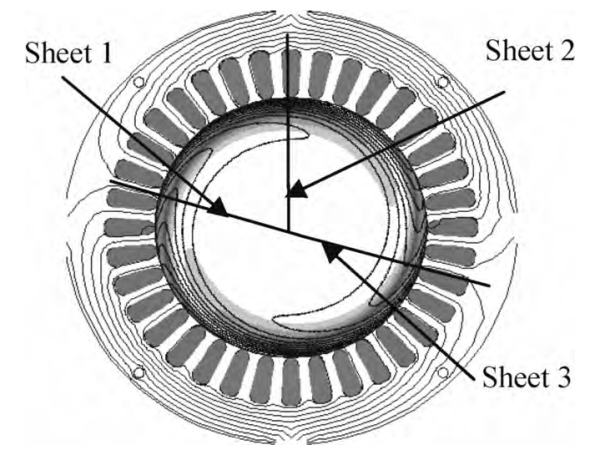

Fig. 12. Current density distribution.
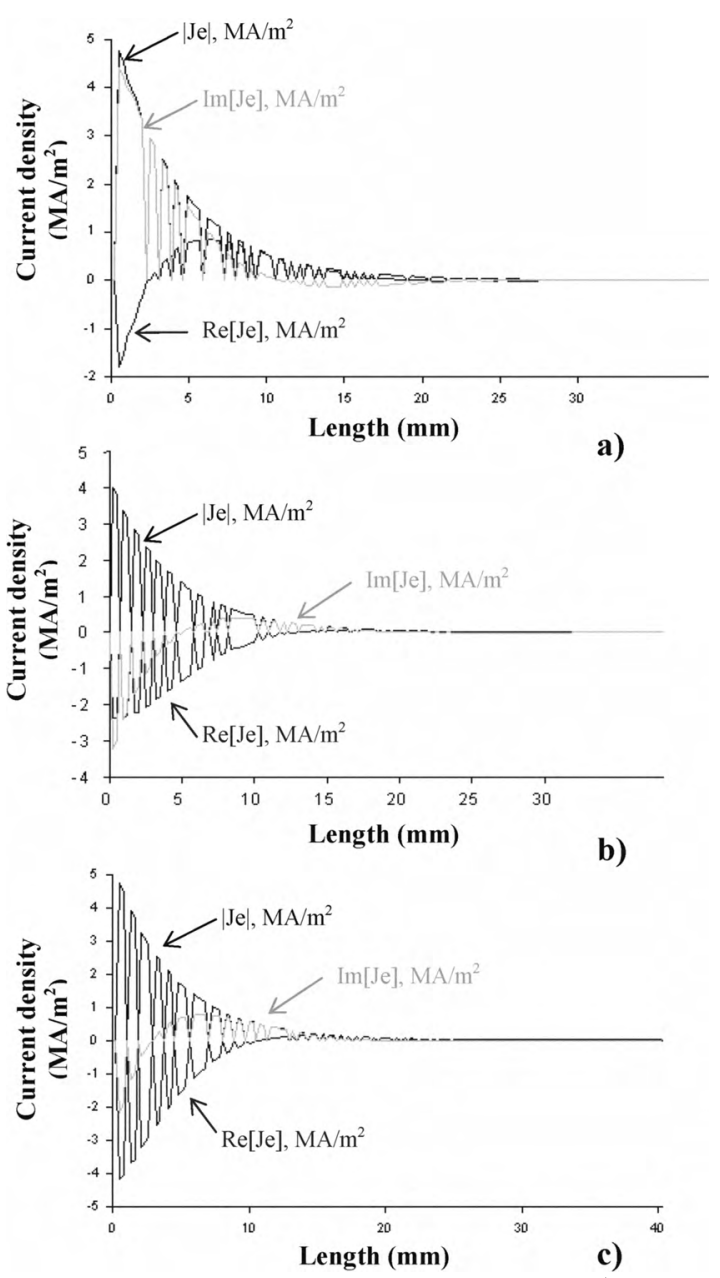

Fig. 13. Current density distribution a) sheet $1, b$ ) sheet 2 , c) sheet 3 .
It is important to see the evolution of current density with the radius, which is represented by a sine wave function as was expected. This current density versus the rotor radius follows a hyperbolic distribution, or more precisely, it follows a hyperbolic tangent. The values of some electric magnitudes can also be observed in these graphs. For example, the value of maximum current density in the rotor is approximately 1.6 $\mathrm{A} / \mathrm{mm}^{2}$.

\section{THERMAL VALUES}

Thermal experiments demonstrate that the motors present different characteristics with respect to conventional squirrel cage motors since the current, which is the main cause of the increase in stator winds temperature, practically does not change when changing the load [8], as shown in figures 14 and 15. This makes these motors able to work in regimes with high slip without changing their thermal conditions. This fact is almost impossible in squirrel cage motors.

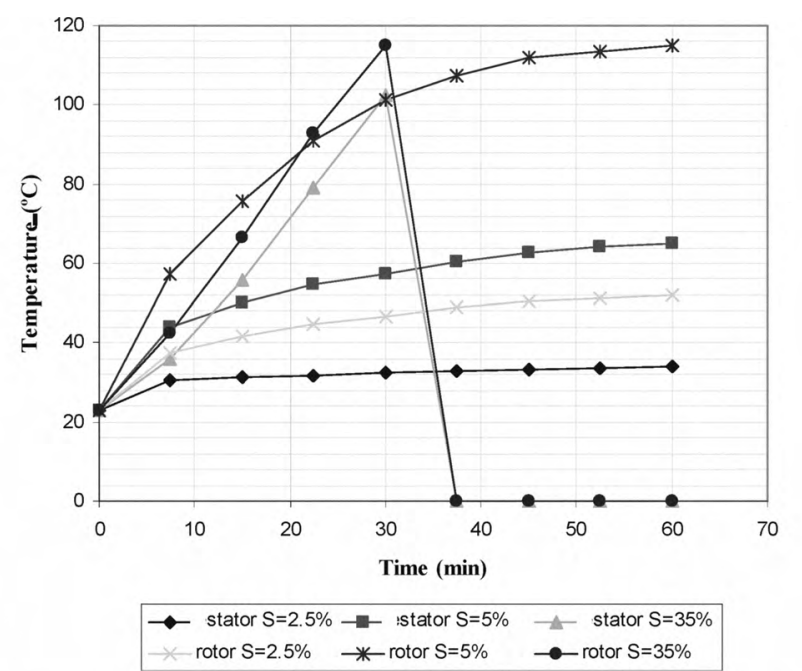

Fig. 14. Thermal test of motor with squirrel cage rotor at $3000 \mathrm{rpm}$ : evolution of rotor-stator temperature.

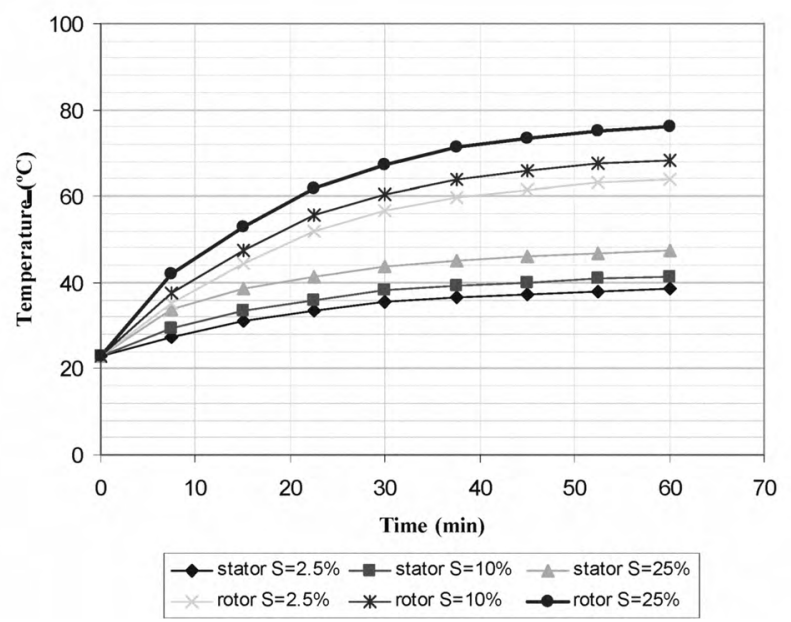

Fig. 15. Thermal test of motor with spiral sheet rotor at $3000 \mathrm{rpm}$ : evolution of rotor-stator temperature 
On the other hand, the spiral sheet motors are more resistant than squirrel cage motors and we can appreciate an increase of temperature with respect to squirrel cage rotors when they are working in the same conditions, but it is in any case much smaller than the increase that other rotors like the solid rotor undergo.

\section{Electric VAlues}

The following graphs (figure 16) compare the behavior of a motor with a type A class spiral sheet rotor with a conventional squirrel cage motor, a motor with a solid rotor with rings and a diamagnetic hollow rotor, all rotating at $3000 \mathrm{rpm}$.
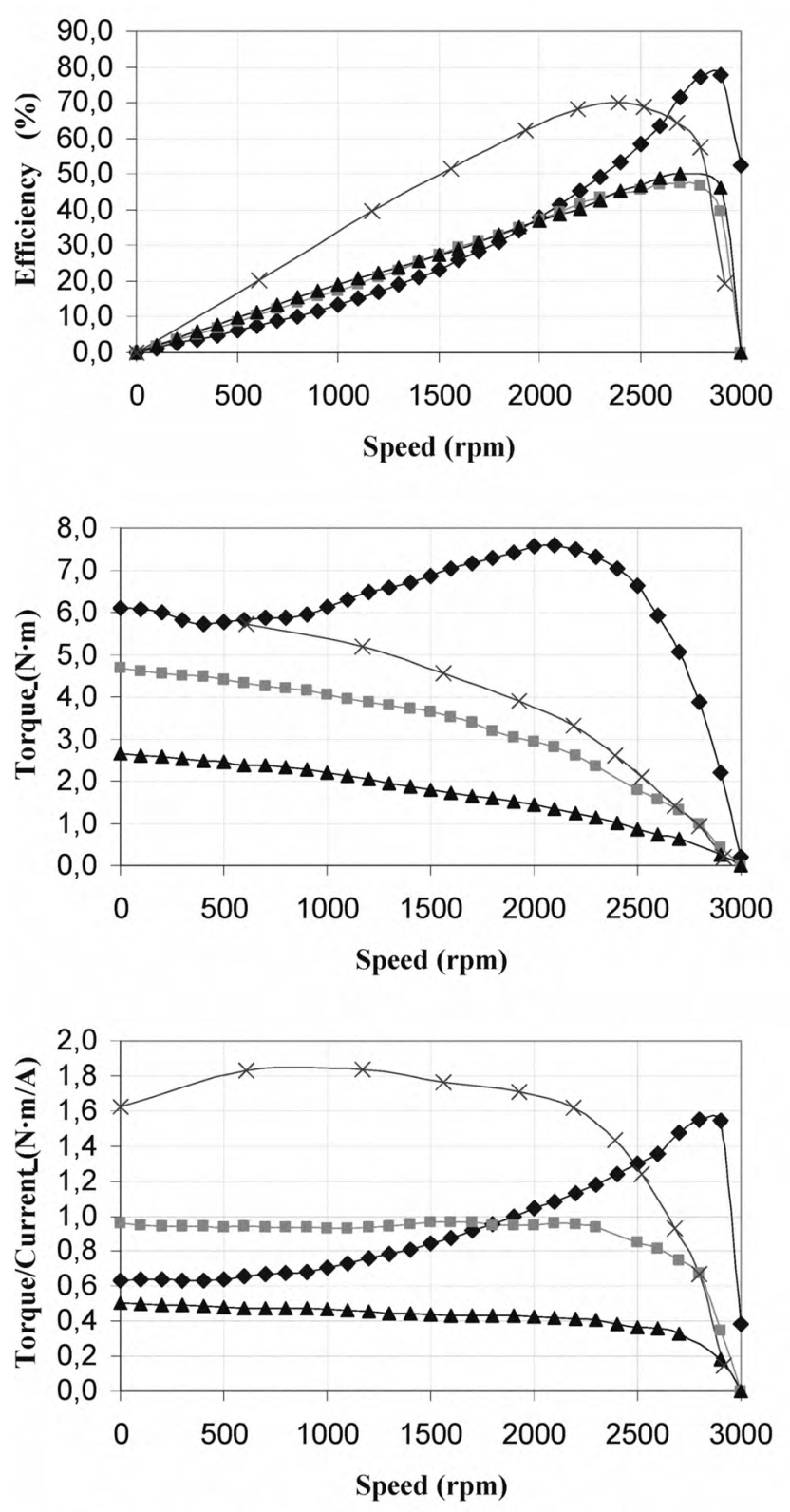

It is observed that the motor with spiral sheet rotor shows better electrical behavior than the motor with a solid rotor, which is its closest competitor. In comparison with the squirrel cage motor, the motor with spiral sheet rotor has very favourable torque/current and torque/power ratios; thus its performance is higher than the cage motor, with the exception of the last phase of the graph. Finally, torque is always lower than that obtained by the squirrel cage motor.

It could be understood that the advantages of the motor with spiral sheet rotor are given for unrated operating conditions (slip of 2-3\%). However, as verified by the thermal, mechanical and magnetic analyses, and unlike the squirrel cage motor, the motor with spiral sheet rotor can work continuously under higher slip values.
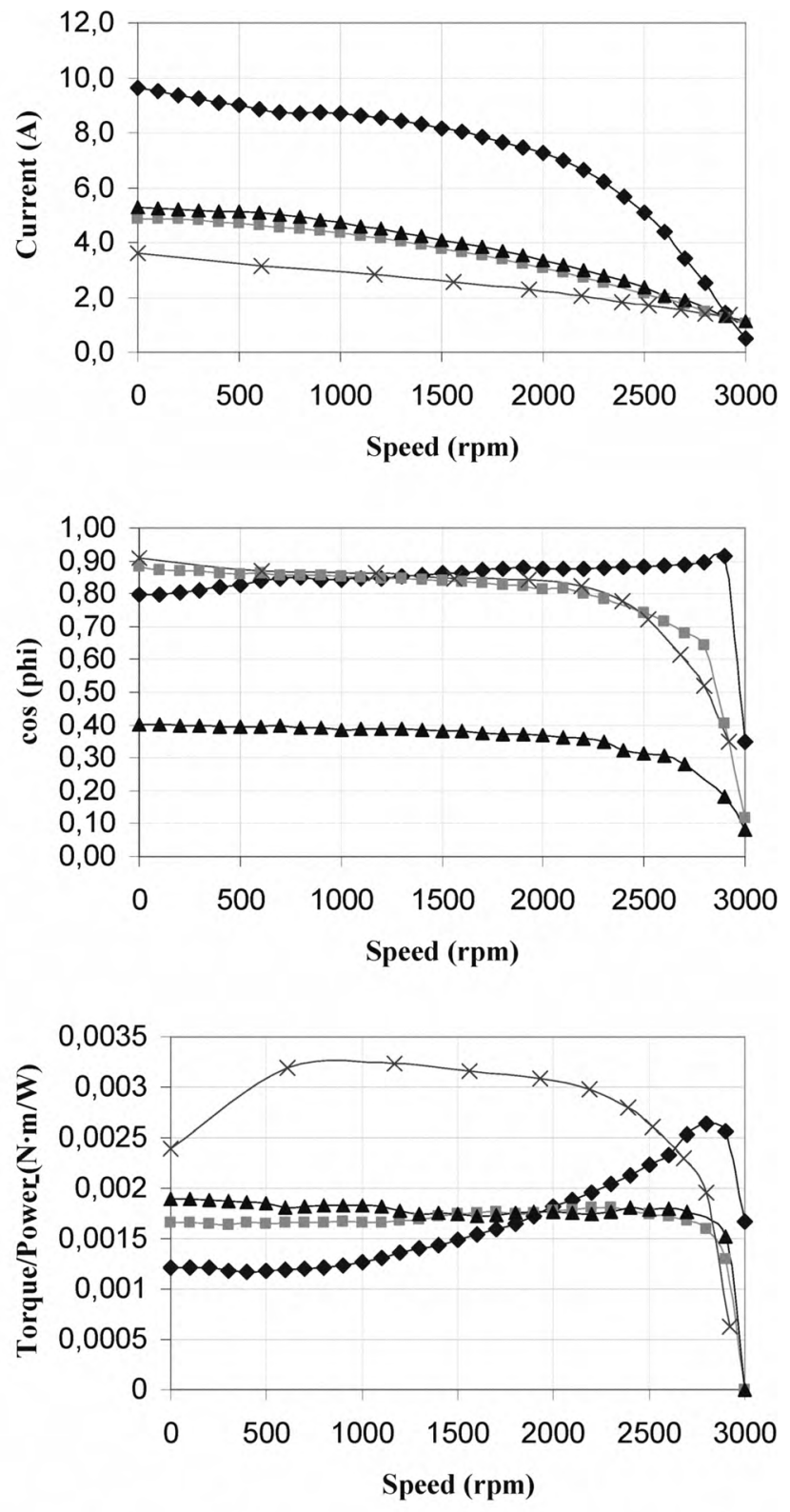

$\longrightarrow$ Spiral sheet type A

Fig. 16. Experimental results using different types of rotors (at 3000rpm). 


\section{MECHANICAL INERTIAS AND LOSSES}

The study of mechanical losses owing to the bearings, fan and air friction has been made, getting reasonable values compared to the rest of conventional motors [1]. The inertias are very similar to squirrel cage motor values; and in the worst case a light inertia increase in the spiral sheet motor are detected, which do not have a machined rotor, as can be seen in figures 17 and 18 , in a stop-start cycle.

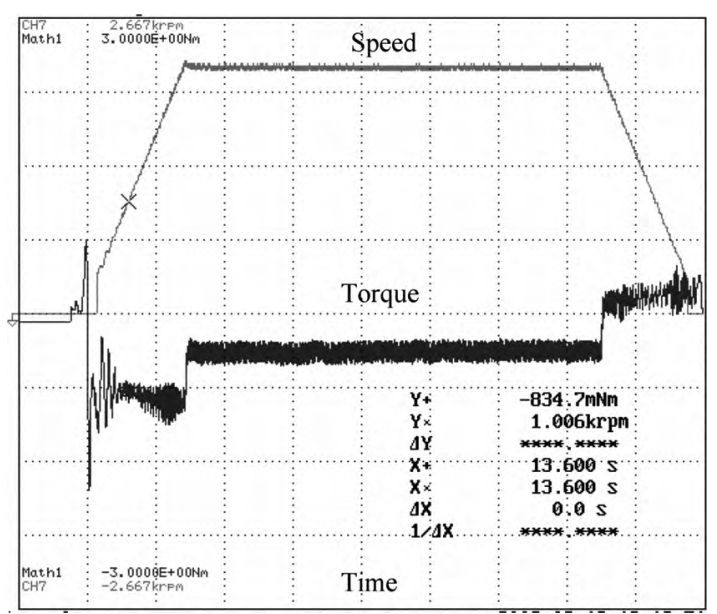

Fig. 17. Torque and speed in a stop-start cycle of a motor with squirrel cage rotor. Torque $0.75 \mathrm{~N} \cdot \mathrm{m} / \mathrm{div}$; Speed $667 \mathrm{rpm} / \mathrm{div}$; Time $1 \mathrm{~s} / \mathrm{dv}$.

Finally, the experiments done to test mechanical resistance in long term operation were satisfactory because although these rotors were not designed for periods of prolonged operations, they have not undergone any type of deformation.

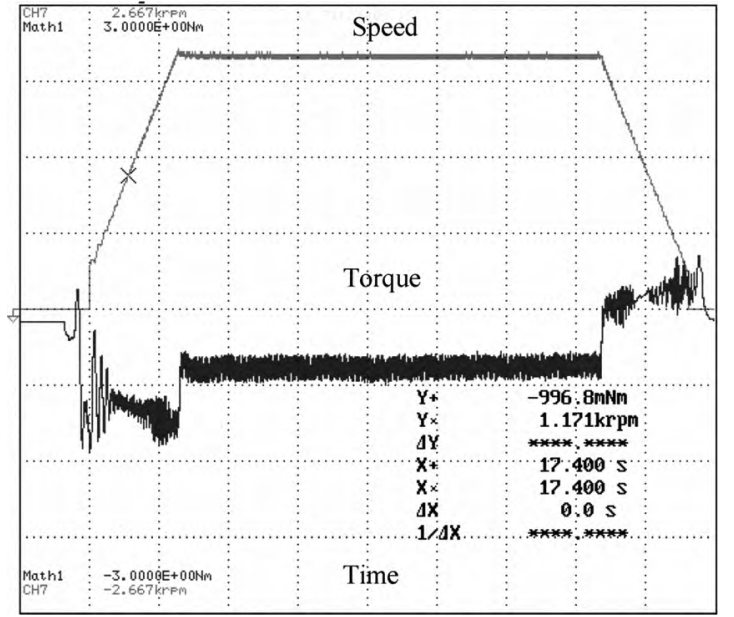

Fig. 18. Torque and speed in a stop-start cycle of a motor with spiral sheet rotor type A. Torque $0.75 \mathrm{~N} \cdot \mathrm{m} / \mathrm{div}$; Speed $667 \mathrm{rpm} / \mathrm{div}$; Time $1 \mathrm{~s} / \mathrm{div}$.

\section{PARASITIC CURRENTS}

Using simulation and a normal section test, it is possible to know the induction in a rotor (figures 19 and 20).

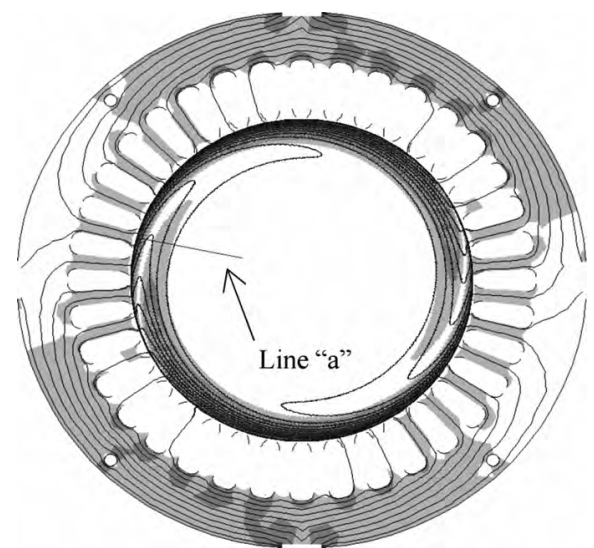

Fig. 19. Magnetic simulation with FEMM. Line "a" represents the section of simulation.

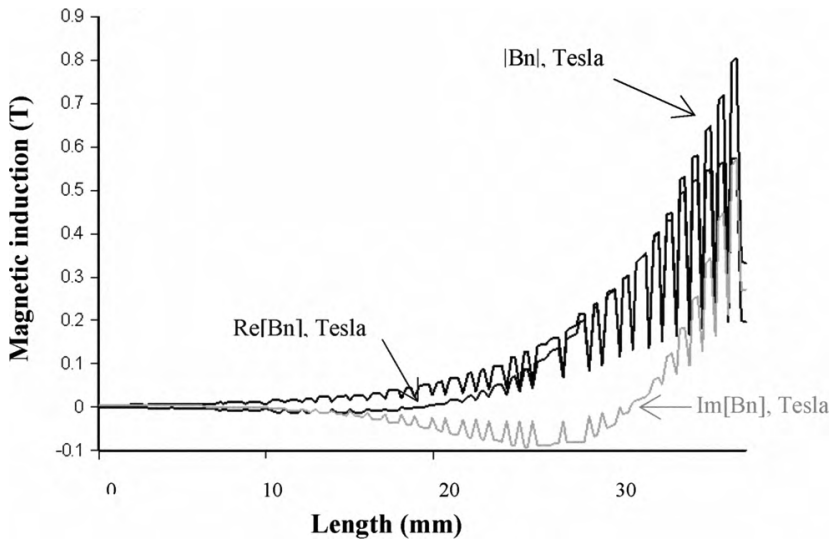

Fig. 20. Magnetic induction. Sheet rotor at $3000 \mathrm{rpm}, \mathrm{c}=3 \mathrm{MS} / \mathrm{m}$, $\mu=4000 \mathrm{H} / \mathrm{m}$, and $\mathrm{f}=3.33 \mathrm{~Hz}$.

With this distribution, the e.m.f. results:

$$
E=-\frac{\partial \phi}{\partial t}=-\frac{\partial B}{\partial t} S=-S \cdot B \cdot w_{S} \cdot \cos w_{S} t
$$

Where $S$ is the magnetic circuit area, a constant in this case.

The current induced by this EMF in sheets can be calculated using the respective electric circuits, remembering that current flows inside the sheets. The EMF distribution is shown in figure 21 .

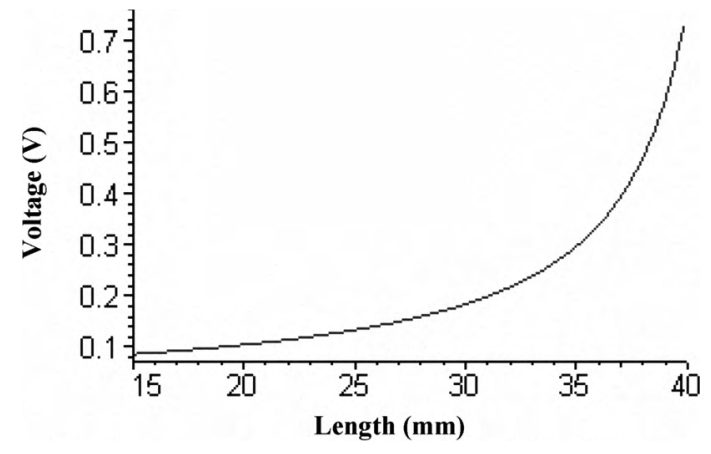

Fig. 21. EMF distribution (distance from stator axis). 


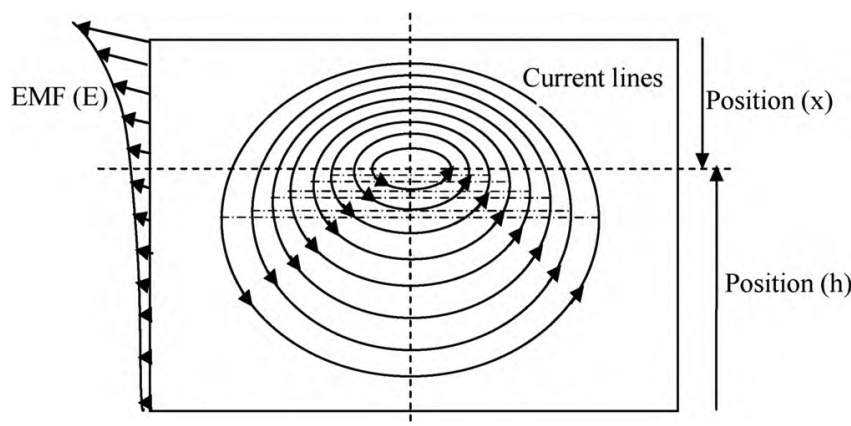

Fig. 22. Vertical coordinate defining the current sense change.

This distribution is owing to the EMF in the upper area of the sheets inducing a higher current in this section (see figure 22). The maximum current can be calculated ( $r$ is the height of the sheets from the rotor axis center):

$$
\begin{gathered}
\left|\bar{E}_{1}\right|=\int_{R_{\text {axis }}}^{h} \frac{k}{(A-r)} d r=k \cdot \ln \frac{A-R_{\text {axis }}}{A-h} \\
\left|\bar{E}_{2}\right|=\int_{h}^{R_{\text {stator }}} \frac{k}{(A-r)} d r=k \cdot \ln \frac{A-h}{A-R_{\text {stator }}} \\
R_{\text {sheet }}=\left(R_{1}+R_{2}\right)=\rho_{\text {sheet }} \frac{L_{\text {rotor }}}{e_{\text {sheet }}\left(\frac{\left(R_{\text {stator }}-s\right)}{h \cdot\left(R_{\text {stator }}-h-s\right)}\right)} \\
\left(E_{1}-E_{2}\right)=I\left(R_{1}+R_{2}\right)=k \cdot \ln \left[\frac{(A-h)^{2}}{\left(A-R_{\text {axis }}\right) \cdot\left(A-R_{\text {stator }}\right)}\right] \\
I=\frac{\rho_{\text {sheet }} \cdot L_{\text {rotor }}\left(\frac{\left(R_{\text {stator }}-s\right)}{\left(h \cdot\left(R_{\text {stator }}-h-s\right)\right)}\right)}{e_{\text {sheet }}\left[\frac{(A-h)^{2}}{\left(A-R_{\text {axis }}\right) \cdot\left(A-R_{\text {stator }}\right)}\right]}
\end{gathered}
$$

Where the constants $A, K, \mathrm{y} k$, are values that adjust the electromagnetic field equation; $s$ is a parameter that depends upon the current circulating through the upper sheet area. Also, $h$ is the sheet radius; $\mathrm{e}_{\text {axis }}$ the sheet thickness (mm); $\sigma$ is the sheet conductivity $\left(\mathrm{S} \cdot \mathrm{m} / \mathrm{mm}^{2}\right)$ and $L_{\text {rotor }}$ is the rotor length.

As the induction is a function of the radial position of the considered section, which is known; it is possible to calculate the constants $A$ and $K$.:

$$
\begin{gathered}
B_{\max }=\frac{K}{\left(A-R_{\text {stator }}\right)} ; A=\frac{B_{\min } \cdot R_{\text {rotor }}-R_{\text {stator }} \cdot B_{\max }}{B_{\min }-B_{\max }} \\
B_{\min }=\frac{K}{\left(A-R_{\text {rotor }}\right)} ; K=B_{\min } \cdot\left(A-R_{\text {rotor }}\right)
\end{gathered}
$$

And $k$ is a constant function of maximum emf:

$$
\begin{gathered}
E=\frac{k}{(A-r)} ; k=E_{\max -2}\left(A-R_{\text {stator }}\right) \\
E_{\max -2}=E_{\max -1} \cdot\left(\frac{m_{1}}{m_{2}}\right) \cdot\left(\frac{Z_{2} \cdot \xi_{2}}{Z_{1} \cdot \xi_{1}}\right)
\end{gathered}
$$

Where:

- $m_{1}$ and $m_{2}=$ number of phases of stator and rotor.

- $Z_{1}$ and $Z_{2}=$ number of turns and sheets of stator and rotor.

$-\xi_{1}$ and $\xi_{2}=$ distribution factors for stator and rotor.

All the terms are known except the radial coordinate $h$ which corresponds to a change of sense in current along the shape profile.

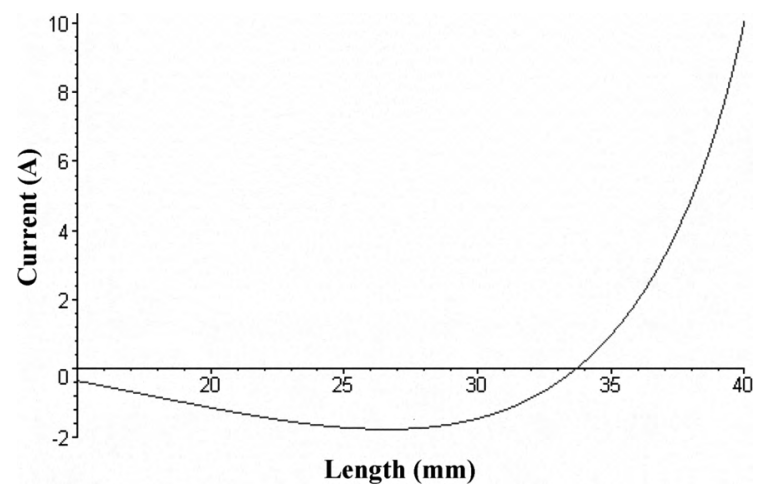

Fig. 23. Distribution of the active current along the radial sheet of the rotor

With the coordinate $h$ known, it is possible to calculate the total sheet current, by integration of the current equation between the upper a lower limits of the sheet (the distribution of the active current along the radial sheet is shown in figure 23):

$$
\begin{aligned}
& I_{\text {upper }}=
\end{aligned}
$$

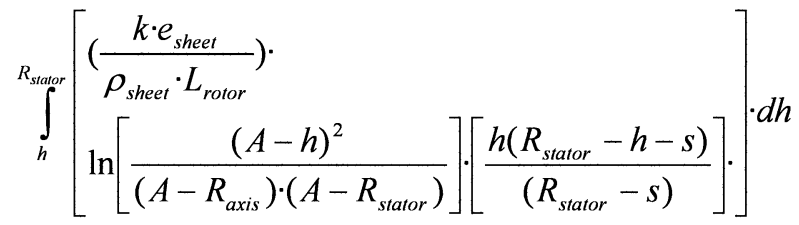

$$
\begin{aligned}
& I_{\text {lower }}= \\
& \int_{R_{\text {rotor }}}^{h}\left[\begin{array}{l}
\left.\frac{k \cdot e_{\text {sheet }}}{\rho_{\text {sheet }} \cdot L_{\text {rotor }}}\right) \cdot \\
\left.\ln \left[\frac{(A-h)^{2}}{\left(A-R_{\text {axis }}\right) \cdot\left(A-R_{\text {stator }}\right)}\right] \cdot\left[\frac{h\left(R_{\text {stator }}-h-s\right)}{\left(R_{\text {stator }}-s\right)}\right] \cdot\right] \cdot d h
\end{array}\right] \cdot
\end{aligned}
$$

The ring per-sheet current and the total currents are:

$$
\begin{gathered}
I_{\text {ring-per-sheet }}=I_{\text {upper }}-I_{\text {lower }} \\
I_{\text {total-ring }}=\frac{I_{\text {ring-per-sheet }}}{2 p} \frac{n_{\text {rotor-sheets }}}{\pi}
\end{gathered}
$$


The torque is related to this total current:

$$
\begin{gathered}
\tau=\int_{R_{\text {rotor }}}^{R_{\text {stator }}} L_{\text {rotor }} \cdot B(r) \cdot I(r) \cdot d h= \\
L_{\text {rotor }} \int_{R_{\text {rotor }}}^{R_{\text {stator }}}\left[\left(\frac{K}{(A-h)}\right) \cdot\left(\frac{k \cdot e_{\text {sheet }}}{\rho_{\text {sheet }} \cdot L_{\text {rotor }}}\right) \cdot \ln \left[\frac{(A-h)^{2}}{\left(A-R_{\text {axis }}\right) \cdot\left(A-R_{\text {stator }}\right)}\right] \cdot\left(\frac{\left(h \cdot\left(R_{\text {stator }}-h-s\right)\right)}{\left(R_{\text {stator }}-s\right)}\right)\right] \cdot d h
\end{gathered}
$$

\section{CONCLUSION}

The three-phase induction motor with spiral sheet rotor establishes several advantages in relation to conventional induction motors, namely, high starting torque with limited starting current, small current variations against load changes, moderated level of no-load power losses, acceptable efficiency in steady state and good transient response.

The aforementioned performances make the proposed motor suitable for high speed applications with frequent stops and starts, which means, in addition to a good electrical response, this motor should be characterized by good thermal behavior and high constructive robustness to withstand frequent speed variations.

A notable disadvantage is the high construction cost of the proposed motor compared to a conventional induction motor. This is mainly owing to the specialized tools used for mechanizing the sheets of the rotor and their sophisticated assembly. For this reason, this motor should be produced in large manufacturing lots.

Nowadays, a wide scope of applications exist requiring the aforementioned characteristics, notably, small staple fibre motors used in textile industries, drives for household appliances, machine-tools, etc. Therefore, a widespread market could be expected for the proposed motor.

\section{ACKNOWLEDGMENT}

The authors would like to acknowledge the economic support from the "Ministerio de Ciencia y Tecnología de España" under the DPI 2004-03180 Research Project.

\section{REFERENCES}

[1] Xiaodong Li, Qing Wu, Subhasis Nandi, "Performance Analysis of a Three-Phase Induction Machine With Inclined Static Eccentricity," IEEE Transactions on Industry Applications, vol. 43, no. 2, March/April 2007.

[2] D. Gonen, "Analysis of a 2-Phase Drag-Cup Induction machine," IEEE Transactions On Power Apparatus And Systems, vol. 85, pp. 71-76, no. 1, January, 1966.

[3] J.F. Lindsay and T.H. Barton, "Parameter Identification for Squirrel Cage Induction Machines," IEEE Transactions on Power Apparatus and Systems, vol. 92, pp. 1287-1291, no. 1, January, 1996.

[4] R. Mujal and L. Humet, "Asynchronous Motor with spiral sheet rotor," ICEM-2000, pp. 477-482, August 28-30. Helsinki-Finland, 2000.
[5] R. Mujal, "Asynchronous motor with spiral sheet rotor. Improvement of the functional characteristics of the asynchronous motors," ICEMS-2001. pp. 80-84, August 18-20. Shenyang-China, 2001.

[6] R. Mujal, "Three-phase asynchronous motor with spiral sheet rotor Performance improvement of the three-phase induction motors," ISC-2002. August 26-28. Tsukuba (Japan).

[7] R. Mujal, "Three-phase Asynchronous motor with spiral sheet rotor Material effects and analysis," IEEE International Electrical Machines and Drives Conference. pp. 1688-1694, March 1-4. Madison-EEUU, 2003.

[8] R. Mujal, "Electromagnetic Analysis of the induction motor with spiral sheet rotor," EPE 2005, September 12-15. Dresden-Germany, 2005.

[9] R. Mujal, "Analysis of the induction motor with spiral sheet rotor," ICEM 2006, September 4-6. Crete-Greece, 2006.

[10] R. Mujal, and O. Boix, "Improvements of three phase induction motor with spiral sheet rotor," IEEE International Symposium on Industrial Electronics. ISIE 2007. pp. 1107-1112, June 4-7. Vigo-Spain, 2007.

Ramon Mujal Rosas was born in Cardona (Spain). He obtained a degree in electrical engineering and a PhD in electrical engineering from the Technical University of Catalonia in 1993 and 2004 respectively.

$\mathrm{He}$ is a professor in the Electrical Engineering Department of the Technical University of Catalonia.

Dr. Mujal is author of some books about electrical subjects, and he is working in remote learning and special electrical machines areas.

Oriol Boix Aragonès (M'00-SM'06) was born in Barcelona (Spain). He obtained a degree in electrical engineering and a $\mathrm{PhD}$ in electrical engineering from the Technical University of Catalonia in 1988 and 1997 respectively.

$\mathrm{He}$ is a professor in the Electrical Engineering Department of the Technical University of Catalonia.

Dr. Boix is working in internet-based learning, harmonics and power quality areas.

Xavier Colom Fajula was born in Sant Joan de les Abadesses (Spain). He obtained a degree in chemical engineering and a $\mathrm{PhD}$ in material science from the Technical University of Catalonia in 1991 and 1997 respectively.

$\mathrm{He}$ is a professor in the Chemical Engineering Department of the Technical University of Catalonia.

Dr. Colom is author of several papers about polymer and composite materials, of some books about material science subjects, and referee of diferent journals 